\title{
A BUSCA DO EQUILÍBRIO ENTRE A POSITIVIDADE DO DIREITO E A REALIZAÇÃO DA JUSTIÇA: UMA VISÃO RADBRUCHIANA
}

\author{
Mhardoqueu G. Lima França ${ }^{1}$
}

\section{Resumo}

Em tempos de pouca crença na lei positivada em razão de decisões judiciais que, às vezes, a contraria, importante se faz lançar luz a uma discussão antiga, mas ainda relevante, que é a harmonia entre segurança jurídica e justiça. Nessa perspectiva, o objetivo desse artigo é traçar meios para equilibrar nos pratos da balança os elementos segurança jurídica e a justiça. Como marco teórico da pesquisa foi utilizado o pensamento do jusfilósofo Gustav Radbruch. A metodologia utilizada foi a jurídico-compreensiva e exploratória, tendo como fonte de pesquisa livros, artigos específicos e jurisprudência. Tudo isso, permitiu alcançar o resultado de que é imprescindível a necessidade de se harmonizar a segurança jurídica e a justiça. E se concluiu que no universo do pensamento radbruchiano a fórmula da injustiça extrema dá o equilíbrio necessário entre os elementos, segurança jurídica e justiça, da ideia de direito de Radbruch, levando em consideração a necessidade do direito positivo, mas com vistas a alcançar a justiça.

Palavras-chave: Positivismo Jurídico; Justiça; Segurança jurídica; Equilíbrio; Injustiça extrema; Direito.

\section{INTRODUÇÃO}

Ser humano, ser em si incerto, no que se refere à vida e à morte, busca o certo nas coisas que o cercam, principalmente, nas questões sociais. O ser humano quer certezas sobre o seu patrimônio, sobre as suas condutas e as consequências delas, sobre os atos do Estado para com ele; enfim, acerca daquilo que o rodeia socialmente.

Essa busca do homem por certezas sociais faz com que o direito positivo, a sua obediência e a segurança jurídica andem juntos. A segurança é um dos valores que informa o direito positivo e se encontram extremamente relacionados. A segurança exige a positividade do direito, enquanto a segurança jurídica é uma garantia que decorre da positividade, dando estabilidade às relações jurídicas que o homem estabelece no meio social, é uma garantia de certeza de que as relações jurídicas estabelecidas não serão modificadas de modo imprevisto, afastando a incerteza e a insegurança quanto ao futuro da situação constituída. Além disso, a segurança jurídica garante que cada pessoa saiba e conheça os seus direitos e deveres, da aplicação deles, e de que, para mudá-los, deverá seguir um determinado procedimento previamente fixado.

\footnotetext{
${ }^{1}$ Doutorando e Mestre em Teoria do Direito pelo Programa de Pós-Graduação em Direito da Pontifícia Universidade Católica de Minas Gerais. E-mail: mhardoqueu@yahoo.com.br
} 
Além da positivação do direito, como forma de garantir a segurança das relações humanas na sociedade, a obediência às regras postas é elemento importante. A segurança exige a positivação do direito e a consequente obediência ao direito posto, pois de nada adiantaria a positivação se o direito não fosse cumprido; isso fez com que alguns autores concebessem o direito como uma ordem de coerção, com a finalidade de assegurar o cumprimento daquilo que está posto.

Todavia, buscar a segurança jurídica ao máximo por meio de um direito estritamente legalista pode gerar grandes arbitrariedades. Em razão disso, alguns autores, como Radbruch, entende que o positivismo ou uma das formas de positivismo, contribuiu para as barbaridades cometidas pelo regime nazista.

O presente artigo tem por escopo demonstrar como Gustav Radbruch, por meio de sua teoria, buscou equilibrar a necessidade de positivar o direito e a obediência às regras postas, sem que os valores da justiça e a segurança jurídica sejam violados. A harmonia desses elementos dentro de um ordenamento jurídico é um grande desafio para todos os juristas, e frequentemente debatido sem um consenso, seja na doutrina ou em decisões judiciais.

\section{POSITIVISMO JURÍDICO E SEGURANÇA JURÍDICA}

Alguns positivistas entendem o positivismo jurídico como uma corrente do pensamento jusfilosófico, no qual a expressão direito positivo tem um significado bastante específico, como um direito posto pelo Estado, por meio de normas gerais e abstratas. A ideia central do seu pensamento é fundada na concepção de que o direito é fruto da cultura humana em oposição à concepção do direito natural.

Conceituar o fenômeno do positivismo jurídico não é tarefa fácil, e este não é o propósito do trabalho. $\mathrm{O}$ positivismo não tem um significado unívoco e unânime, isso se deve ao fato de ter apresentado várias formas e concepções em diferentes épocas, guardando peculiaridades histórico-sociais de cada época e de sistema jurídicos diferentes.

Há três teorias que buscam explicar o surgimento do positivismo jurídico: a teoria filosófica, que explica o positivismo jurídico como o desdobramento do positivismo filosófico no campo do direito; a teoria histórica, que aponta o positivismo como fruto de um processo histórico, sendo esta teoria a majoritária entre os estudiosos do assunto; e, por fim, a teoria mista, que concilia as duas teorias acima. É inegável que o surgimento do positivismo jurídico é produto de uma conjunção de fatores, como a ordem histórica, política, filosófica e jurídica, não sendo possível determinar a predominância de um destes fatores (MACHADO, 2011, p. 314).

Apesar de não ser possível definir com precisão o positivismo jurídico ou um dos fatores que determinam o seu surgimento, pode-se apontar a circunstância pela qual este fenômeno jurídico surge, sendo possível notar a influência da segurança jurídica para o estabelecimento do positivismo jurídico. 
Segundo Noberto Bobbio (2006, p. 26), o positivismo jurídico nasce a partir do momento em que o direito positivo e o direito natural já não são mais considerados como direito no mesmo sentido, pois o positivismo jurídico reduz todo o direito a um direito positivo, e o direito natural é excluído da categoria do direito. Isso ocorre no período que coincide com o desenvolvimento do Estado moderno e democrático, em oposição ao Estado absoluto.

É nesse momento que o positivismo jurídico se estabelece e ganha força, pois com o Estado moderno ocorre a queda das teorias naturalista, predominantes na Grécia, Roma e na Idade Média, justificada pela religião ou pela força, ou seja, o Estado deixa de ser considerado expressão divina ou meio de dominação dos fracos pelos fortes (MACHADO, 2011, p. 316).

O Estado moderno surge com a dissolução da sociedade medieval, o que marca a passagem da concepção jusnaturalista à positivista. A sociedade medieval era pluralista, caracterizada por uma diversidade de agrupamentos sociais, cada um dispondo de ordenamento jurídico próprio. O direito apresentava-se como um fenômeno social, produzido pela sociedade civil e, não, pelo Estado. O Estado primitivo, de modo geral, não produzia normas jurídicas, deixava a sua formação a cargo e desenvolvimento da sociedade.

Com a formação do Estado moderno, a sociedade assume uma estrutura monista, no sentido de que o Estado concentra em si todos os poderes, principalmente o poder de criar o direito, quer ser o único a estabelecer o direito, seja por meio da lei ou por meio do reconhecimento e controle das normas de formação consuetudinárias. Tem-se, assim, o processo de monopolização da produção jurídica por parte do Estado (BOBBIO, 2006, p. 27).

Antes da formação do Estado moderno, com a consequente monopolização da produção das leis, o juiz, ao resolver as controvérsias, não se vinculava estritamente às normas estatais, tinha a liberdade de escolher a norma a aplicar, podendo ser regras do costume, as elaboradas pelos juristas e, ainda, em critérios equitativos extraídos do próprio caso segundo princípios da razão natural. Todas essas regras estavam no mesmo nível, e na mesma proporção constituíam as fontes do direito. Isso permitia aos juristas falarem em duas espécies de direito, natural e positivo, permitindo ao juiz obter a norma e aplicá-la por meio de regras preexistentes na sociedade ou de princípios equitativos e da razão (BOBBIO, 2006, p. 28).

Com o Estado moderno o juiz passa de um órgão livre da sociedade para um órgão do Estado, como titular de um dos poderes estatais, o Poder Judiciário, subordinado ao Poder Legislativo. Isso faz com que as normas de direito positivo e direito natural já não sejam mais consideradas no mesmo nível, como na sociedade medieval, passando o direito positivo a ser considerado como o único e verdadeiro direito.

Estas transformações advindas do Estado moderno culminam em duas condicionantes, uma de natureza política e outra de natureza técnico-jurídica. A primeira refere-se às noções de soberania nacional e ao princípio da 
separação dos poderes. A segunda trata do caráter privilegiado que a lei assume como fonte do direito e a concepção do direito como sistema de normas postas (FERRAZJ. ${ }^{\mathrm{R}}$, 1994, p. 74).

A soberania na sociedade medieval residia no senhor territorial ou no rei, esta forma de governo concentrada, concreta e personalíssima simbolizava um centro único de normatividade e assinalava uma organização limitada do poder. A substituição da figura do rei ou do soberano territorial pela concepção de nação permitiu a manutenção do caráter uno, indivisível, inalienável e imprescritível da soberania, indo ao encontro do princípio da divisão dos poderes, que dá origem a concepção de um Poder Judiciário com características autônomas.

A clássica divisão dos poderes construída em oposição à concepção de soberania anterior, marcada pela forma personalíssima, garantiria a progressiva separação entre política e direito. Isso vai regular a legitimidade da influência da política na administração de cada poder, que se torna aceitável no Legislativo, parcialmente no Executivo e neutralizada no Judiciário. A neutralização política do Judiciário significa a canalização da produção do direito para o Legislativo, ocupando a lei um lugar privilegiado; este foi fator importante para o desenvolvimento de uma nova forma de saber jurídico, que é a ciência do direito no século XIX (FERRAZ J.), 1994, p. 74).

A divisão de poderes tem como uma de suas principais funções proteger o cidadão contra as arbitrariedades dos poderes, visando eliminar a liberdade do juiz de aplicar o direito extraído do seu próprio senso de equidade ou da vida social, atribuindo ao legislador o poder de editar normas iguais para todos, mas também resguarda os cidadãos das arbitrariedades do Executivo, não atribuindo a este órgão o poder de legislar, mas, sim, a um órgão colegiado que age paralelamente àquele, com a consequente subordinação do Estado à lei.

Montesquieu (19--), na obra L'Esprit des lois, no livro XI, no qual expõe a teoria da separação dos poderes, demonstra a relação entre Poder Legislativo e o Judiciário. A decisão do juiz deve ser uma reprodução fiel da lei, o juiz não tem qualquer liberdade de exercer a função do Poder Legislativo, pois, se pudesse modificar a lei, o princípio da separação dos poderes seria negado, assim o autor afirma:

Mas, se os tribunais não devem ser fixos, os julgamentos devem ser a tal ponto, que eles nunca sejam mais que um texto preciso da lei. Se eles fossem uma opinião particular do juiz, viver-se-ia na sociedade, sem saber precisamente os compromissos que nela se contrai. (MONTESQUIEU, [19--], p. 144.) (Tradução do nossa.)

A subordinação dos juízes à lei busca garantir a segurança jurídica do direito, de maneira que o cidadão saiba com certeza se o seu comportamento está ou não conforme a lei (BOBBIO, 2006, p. 40).

A divisão dos poderes bem como o processo de positivação das leis ocorre como forma de atribuir aos cidadãos segurança jurídica nas relações consolidadas na sociedade e como forma de limitar os poderes do Estado, uma vez que vinham de um regime absolutista, no qual o rei era a lei e o judiciário o seu dependente, deixando os cidadãos ao arbítrio do soberano, não podendo precisar as leis. 
O direito positivado por meio de leis advém da exigência de pôr ordem no caos e na insegurança jurídica instalada na sociedade medieval. O positivismo jurídico vem para atender à necessidade de segurança jurídica aclamada pela sociedade, como afirma Tércio Sampaio Ferraz J. ${ }^{r}$ (1980, p. 32):

O positivismo jurídico, na verdade, não foi apenas uma tendência científica, mas também esteve ligado, inegavelmente, à necessidade de segurança da sociedade burguesa. $O$ período anterior à Revolução Francesa caracteriza-se pelo enfraquecimento da justiça, mediante o arbítrio inconstante do poder de força, provocando insegurança das decisões judiciárias.

Esta necessidade de resguardar os cidadãos das arbitrariedades do Estado faz com que a positivação se torne um fenômeno representado pela lei como principal fonte do direito. Dar prevalência à lei vem saciar o anseio do homem de modificar a sociedade em que vive, de controlar o meio pelo qual conhece as leis que o rege, podendo revogar, criar, propor medidas legislativas, segundo uma finalidade racional e por meio do direito posto.

A crítica dos pensadores iluministas e a necessidade de segurança jurídica aclamada pela sociedade burguesa passa a exigir uma valorização dos preceitos legais no julgamento dos casos, originando um respeito quase mítico pela lei, base para o desenvolvimento da Escola da Exegese, que influenciou os países em que prevaleceu o espírito napoleônico (FERRAZJ. ${ }^{\mathrm{R}}$, 1994, p. 75).

O nascimento da Escola da Exegese liga-se à exigência de segurança jurídica, como Noberto Bobbio (2006, p. 66) aponta ao relatar os cinco pontos para o seu advento.

O primeiro ponto é representado pela codificação, que surgiu como uma espécie de catálogo para resolver, se não todas, aos menos as principais controvérsias jurídicas. A codificação das normas advém por um grave estado de confusão e incerteza, provocado pela crise do direito, vigente no século XVIII, que era o direito romano de Justiniano, modificado e compilado através de séculos, por variadas fontes, sendo praticamente impossível de ser conhecido com segurança. Em decorrência disso, sentiu-se uma forte necessidade de reformas legislativas que dessem ao direito, principalmente, certeza. E este foi o propósito das codificações entre o fim do século XVIII e início do século XIX (FASSÒ, 1998, p. 659).

O segundo ponto refere-se ao que se denominava, pela mentalidade dos juristas, como o princípio de autoridade. Este princípio deduzia que a vontade do legislador é expressa de modo seguro e completo, e cabe aos operadores do direito ater-se ao editado pela autoridade soberana.

O terceiro ponto refere-se à já tratada teoria da separação dos poderes, na qual se estrutura o Estado moderno, com a divisão de competências e da atribuição das três funções fundamentais do Estado.

O quarto ponto é representado pelo princípio da certeza do direito, segundo o qual os cidadãos exigem do direito um critério seguro de conduta que deve ser conhecido antecipadamente, com exatidão, das consequências de seu comportamento. Esta certeza só é garantida quando há um corpo estável de leis e delas são extraídos os critérios para resolver as controvérsias. De outro modo, as decisões seriam arbitrárias e os cidadãos não conheceriam com exatidão as consequências das próprias ações. A exigência de segurança jurídica faz com 
que o jurista renuncie a criação interpretativa da lei, limitando-se à aplicação do texto normativo.

O quinto e último ponto trata das pressões exercidas pelo regime napoleônico no ensino superior de direito, para que fosse ensinado somente o direito positivo em detrimento das teorias gerais do direito e as concepções jusnaturalistas.

O fundamento da Escola da Exegese, como estudo do direito era a doutrina legalista, ou seja, todo direito está na lei. "Só o legislador, agindo em nome da nação soberana, tem o poder de elaborar o direito. Não pode, portanto, existir outra fonte de direito senão a lei” (GLISSEN, 1995, p. 516). Por isso recebeu o nome de positivismolegal.

De acordo com John Glissen (1995, p. 516), a Escola da Exegese dominou a ciência do direito na França e na maior parte da Europa continental de 1830 a 1880, e ainda exerce, nos tempos atuais, profunda influência sobre o ensino jurídico e a prática do direito.

Para alguns estudiosos do direito o positivismo legalista, no qual a lei é todo o direito "[ ... ] produziu o dogma da soberania absoluta do Estado que se encontra nas teorias nacional-socialistas do século XX e, sobretudo, na concepção soviética do direito" (GLISSEN, 1995, p. 518).

Neste ponto não se objetiva reproduzir a crítica de que o positivismo jurídico foi o sustentáculo ideológico dos regimes totalitaristas no campo do Direito, a partir da afirmação de que por mais injustas que fossem as normas ditadas pelos regimes totalitários, eram consideradas direito à luz do direito positivo. Considerando que este raciocínio é simplório, precário e ingênuo, como afirma Latorre (2002, p. 153), esta afirmativa está associada à velha acusação de amoralidade, que frequentemente se faz ao positivismo.

Deste modo, prefere-se entender que, os regimes totalitários deturparam ideologias, utilizando delas para alcançar os fins pretendidos. Para alguns teóricos do direito o positivismo, na sua concepção mais legalista, foi utilizado pelo regime nacional-socialista, deixando "[... ] sem defesa o povo e os juristas contra as leis mais arbitrarias, mais cruéis e mais criminosas" (RADBRUCH, 1979, p. 415). Para além da discussão se o positivismo foi ou não sustentáculo do regime nazista, como afirma Elza Maria Miranda Afonso (1999, p. 56), entende-se que "[...] o problema do autoritarismo não está, definitivamente, na crença em valores relativos, mas no desrespeito ao valor da pessoa, na prepotência, na arrogância e no abuso do poder".

O certo é que, a partir do final da Segunda Guerra Mundial, juristas alemães se insurgiram contra essa concepção legalista do positivismo, a fim de não se verem de mão atadas diante de arbitrariedade como as ocorridas no nazismo. A primeira reação notória foi a de Gustav Radbruch, que percebeu o conflito dos elementos que compõem a sua ideia de Direito, adequação ao fim, segurança jurídica e justiça, que interferem na aplicação prática do direito, afirmando que, em toda vez que o conflito entre a justiça e a segurança jurídica for tão insuportável a ponto de violar direitos humanos, deve prevalecer a justiça. Passa-se então ao pensamento deste 
autor, na busca de um equilíbrio entre a necessidade de um direito posto, como forma de efetivar a segurança jurídica, mas, sem deixar de lado a justiça.

\section{A RELAÇÃO ENTRE SEGURANÇA JURÍDICA E A JUSTIÇA NA TEORIA DO DIREITO DE GUSTAV RADBRUCH}

Gustav Radbruch foi professor de direito penal e de filosofia jurídica nas Universidades de Königsberg, Kiel e Heidelberg. Na década de 1920, foi deputado ao Reichstag e ministro da Justiça. Em 7 de abril de 1933, Radbruch foi afastado de sua cátedra na Universidade de Heidelberg, por razões políticas advindas do regime nazista, retornando a ela no ano de 1945, após a queda do regime nazista, como decano da Faculdade de Direito, onde exerceu suas funções até o seu falecimento, em 23 de novembro de 1949.

A relevância do pensamento deste autor excede o clássico recurso ao jusnaturalismo para mostrar, por meio do testemunho de sua conversão teórica as consequências que o positivismo jurídico estrito trouxe consigo. Autores de destaque vêm ocupando-se do pensamento radbruchiano, como Arthur Kaufmann, que reconhece que a filosofia do direito de Radbruch propõe uma mudança de paradigma, intentando superar as alternativas jusnaturalismo e juspositivismo. Robert Alexy também se utiliza da teoria de Radbruch ao considerar o problema da validade do direito. No mesmo sentido, a jurisprudência do Tribunal Constitucional alemão já invocou a autoridade do pensamento deste autor para fundamentar decisões de casos relevantes (VIGO, 2008. p. 22). Notase também que a obra deste autor tem recobrado importância nas questões em que necessitam de respostas do direito nos casos de grave injustiça.

Neste contexto é importante deixar claro que as ideias de Radbruch aqui expostas são as firmadas após a Segunda Guerra Mundial, quando teria mudado o seu pensamento em decorrência do regime nazista. Alguns autores, por terem identificado substanciais mudanças no pensamento deste autor, afirmam que houve uma ruptura na teoria de Radbruch; entre eles podem-se citar Hippel, Fuller, Hart, Verdross, Villey, Guido Fassò, Engisch, Spendel e outros. Existem também autores que asseveram que não houve uma ruptura no pensamento radbruchiano, mas, uma continuidade da sua teoria, entre os quais se podem citar Wolf, Kaufmann e Muller (VIGO, 2008, p. 43).

Sem entrar na questão se houve ou não uma conversão de Radbruch, não se pode deixar de notar que o regime nazista de um modo ou de outro influenciou o pensamento deste autor; isso resta claro em seu discurso por ocasião da reabertura da Faculdade de Direito da Universidade de Heidelberg, em 1946, quando afirmou:

Recordamos estes doze anos repletos de injustiça e arbitrariedades; recordamos um domínio do poder estatal que considerava que estava permitido tudo aquilo que o parecia útil e que insensatamente prescindia de leis válidas, mesmo quando estas serviram para o sagrado fim da proteção da vida humana ... Recordamos um tempo no qual as leis tinham que servir para sancionar a injustiça e o crime. (RADBRUCH apudSICHES, 1971, p. 244.) 


\section{(Tradução nossa.)}

Radbruch atribuía uma considerável dose de responsabilidade ao positivismo jurídico pela implantação do Estado totalitário e do desenvolvimento de seu regime; esta responsabilidade consiste em haver ensinado o postulado da obediência incontestável à lei positiva (SICHES, 1971, p. 244).

$\mathrm{Na}$ perspectiva de entender melhor a relação entre justiça e segurança jurídica, visando a mitigar a obediência absoluta ao direito positivo pregado pelo positivismo legalista, é necessário abordar questões iniciais do pensamento de Radbruch, construídos nas obras Filosofia do direito e Introdução à filosofia do direito, para entender o seu conceito e ideia de direito.

\section{O dualismo e relativismo de valores}

Radbruch inicia a sua obra Filosofia do direito (1932) sustentando as bases do seu pensamento a partir da distinção realidade e valor. Afirma que "[...] a primeira ação voluntária do espírito é a de apartar o eu do dado e contrapô-los a fim de separar a realidade do valor" (RADBRUCH, 2004, p. 5). Assim, suscita a possibilidade de dois tipos de atitudes básicas; a atitude cega para o valor, própria do pensamento das ciências naturais; e a atitude valorativa, executada de modo sistemático, que caracteriza a filosofia dos valores em seus três ramos: a lógica, a ética, e a estética (RADBRUCH, 2004, p. 6).

A essas duas atitudes o autor agrega outras duas que têm a função mediadora; atitude que se refere a valores que constroem as ciências culturais (RADBRUCH, 2004, p. 6); e, por fim, atitude superadora de valores, característica típica das atitudes religiosas (RADBRUCH, 2004, p. 7).

Essas quatro atitudes correspondem ao que Radbruch denomina de “[...] forma quádrupla do dado: ser, valor, sentido e essência" (RADBRUCH, 2004, p. 10), e a relação entre eles expressa-se pela natureza e ideal e sobre o abismo que existe entre estes elementos.

Feitas estas constatações, Radbruch põe a classificar o direito dentro de uma dessas quatro perspectivas, e faz três considerações possíveis: o direito como fato cultural, que é a essência da ciência do direito; o direito como valor cultural, que caracteriza a filosofia do direito; e, por fim, o direito como superador do valor, que considera a essência ou a não essência do direito, o que caracteriza uma filosofia religiosa do direito (RADBRUCH, 2004, p. 12).

Para Radbruch (2004, p. 10) o direito é uma obra humana impregnada de valor e, como tal, só pode ser compreendido a partir de sua ideia. Assim, afirma:

O direito é uma manifestação cultural, isto é, um fato relacionado a um valor. O conceito do direito não pode ser determinado de modo diferente do que o dado, cujo sentido é de tornar real a ideia do direito. O direito pode ser injusto (summum ius - summa iniuria), mas só é direito por ter o sentido de ser justo. (RADBRUCH, 2004, p. 11.)

A cultura é uma espécie de ponte entre natureza ou realidade e o ideal ou valor, por isso que considera o 
direito uma realidade ligada a valores, um fenômeno cultural.

A questão valorativa está fortemente presente em Radbruch, tanto que para este autor, o objeto de estudo da filosofia do direito é o valor do direito ou do direito ideal, levando-o a afirmar que a filosofia do direito é “[...] a consideração valorativa do direito, a doutrina do direito justo”” (RADBRUCH, 2004, p. 13). Para Radbruch (2004, p. 17) a filosofia do direito não tem apenas a tarefa de refletir sobre o juízo de valor jurídico, mas, também, de indicar os meios indispensáveis e suas consequências para alcançar o fim jurídico, ou seja, o que leva a realizar o direito ideal.

Por outro lado, a ciência jurídica em Radbruch (2004, p. 14) “[...] tem a pretensão de derivar a regulação justa a partir da 'natureza das coisas”'. A ciência jurídica caracteriza-se por ser dogmática e sistemática, ocupandose do sentido objetivo de uma ordenação jurídica e, não, do sentido subjetivo; é uma ciência do direito vigente e, não, do direito justo, não se ocupa do direito como deveria ser, mas, como é.

Seu objeto são os ordenamentos. Não é uma ciência do direito justo, mas do direito vigente; não do direito que deveria ser, mas o que é. Distingue-se daquelas ciências do direito que tem por objeto o direito que deve ser; da filosofia do direito - a ciência dos fins jurídicos - e da política do direito, a ciência dos meios para atingir os fins. (RADBRUCH, 2004, p. 161.)

A partir de tais considerações, verifica-se o método dual de Radbruch, que impossibilita deduzir o ser do dever-ser. Alicerçado no pensamento kantiano, afirma que não há ligação entre o ser e o dever ser, entre realidade e valor, "[...] as proposições do dever ser só podem derivar-se dedutivamente de outras proposições do dever ser, não podendo fundamentar-se indutivamente de fatos do ser" (RADBRUCH, 2004, p. 15) e, por sua vez, "[...] as proposições últimas do dever-ser são indemonstráveis, axiomáticas, não passíveis de conhecimento, mas apenas de crença" (RADBRUCH, 2004, p. 17).

Radbruch deixa expresso o abismo que há entre a realidade e o ideal (valor), destaca a distância existente entre o direito pensado e o positivado, entre o direito que a filosofia do direito se reserva para o direito da ciência jurídica.

Para atenuar o dualismo entre o ser e o dever ser, entre a realidade e o valor, Radbruch formula o que denomina de natureza da coisa "A natureza da coisa é a pauta de todos aqueles que se esforçam para minorar o rude dualismo entre ser e dever ser, realidade e valor, buscando a razão nos entes" (RADBRUCH, 2009, p. 53) (Tradução nossa.).

Nos últimos escritos, dedicou-se à natureza da coisa como meio de reduzir a distância entre ser e dever ser. Radbruch (2009, p. 56) adverte que não se deve entender a natureza da coisa como uma forma de pensar do jusnaturalista. O direito natural, da natureza do homem, aspira fundar um direito igual para todos os povos em todos os tempos; por outro lado, a natureza da coisa evidencia a variedade de construções jurídicas nacionais e históricas.

A natureza da coisa revela que a ação ordenada ou estruturante do direito se produz com e para 
determinadas realidades humanas e situações sociais (SICHES, 1971, p. 244). É uma relação vital comunicada por uma ideia jurídica, é o sentido de uma relação fática, é o reflexo de uma ideia jurídica (RADBRUCH, 2009, p. 65). Com isso quer dizer que a expressão natureza da coisa significa que se deve levar em conta a realidade por meio de dados concretos, para que se busque a razão nas coisas, na realidade.

Por outro lado, explica que a natureza da coisa não é válida em si mesma e não é fonte do direito, só é válida quando uma fonte do direito permite a sua utilização de forma expressa ou tácita. É um meio de interpretação, é uma forma de preencher lacunas, mas, limitado até o ponto em que as relações vitais que se transmite a ideia em que se funda a natureza da coisa, não se contradizem com o espírito da lei (RADBRUCH, 2009, p. 65).

Com o objetivo de minorar o abismo entre o ser e dever ser, Radbruch (2009, p. 66) defende que a natureza da coisa deve ser observada pelo legislador e que é uma guia dominante da ideia do direito. A ideia do direito não só deve levar em consideração a natureza do direito, mas, muitas vezes, é determinada internamente pela natureza da coisa e esta está inseparavelmente fundida à ideia do direito.

A natureza da coisa, como conclui Radbruch, serve para aliviar um pouco a tensão do dualismo entre ser e dever ser, mas, sem fazer desaparecê-lo, e alerta para que, ao se falar em valores, se deve estar consciente da influência ou da determinabilidade que a realidade tem sobre eles.

Interligado ao dualismo e à tentativa de diminuir a distância entre ser e dever ser, encontra-se a temática do relativismo dos valores. O problema do relativismo na obra de Radbruch é desenvolvido em contraposição ao direito natural, que se apoia num princípio metodológico concreto, que entende existir uma ideia de direito justo, unívoco, reconhecível e demonstrável (RADBRUCH, 1934, p. 105). Para Radbruch os valores são percebidos pelo dever ser, portanto não são suscetíveis de conhecimento ou fundamentação científica. Por isso, nem a ciência nem a filosofia podem estabelecer qual valor deve prevalecer sobre o outro; no caso do direito afirma:

A filosofia do direito relativista é incapaz de determinar, para o indivíduo, a escolha entre as concepções jurídicas de pressupostos últimos e contrários. Ela se limita a apresentar-lhe, de modo exaustivo, as possibilidades de tomada de posição, mas abandona a própria tomada de posição à sua decisão criada nas profundezas da personalidade - portanto, não do seu arbítrio, mas, antes da sua consciência. (RADBRUCH, 2004, p. 19.)

O relativismo filosófico parte da tese de que cada conceito de um conteúdo do direito justo só é válido com base no pressuposto de uma determinada situação da sociedade num sistema concreto de valores (RADBRUCH, 1934, p. 105). O relativismo busca precisar a qualidade de justo de cada juízo valorativo, somente em relação com outro juízo de valor determinado e superior, sob os limites de uma concepção determinada do próprio valor e do mundo, sem se preocupar em fixar tal concepção.

Isso significa de um lado que relativismo renuncia à razão teórica, e dá maior relevância à razão prática, o que não quer dizer um abandono total à razão teórica, mas, uma renúncia científica às atitudes supremas, não cede, 
porém, à tomada de uma posição.

Por fim, o relativismo é mais que um método da filosofia do direito. "Sobre tudo, o relativismo é o fundamento único da força obrigatória do direito positivo" (RADBRUCH, 1934, p. 106) (Tradução nossa). Radbruch argumenta que, se houvesse um direito natural, uma verdade unívoca, não teria razão a força vinculante do direito positivo, o que seria uma contradição com a verdade absoluta. A força obrigatória do direito só pode fundar-se precisamente no fato de que o direito não é reconhecível, nem demonstrável. Um juízo sobre a verdade ou falsidade das diferentes convicções jurídicas é impossível. Por outro lado, no bojo social, se se requiser um direito único para todos os sujeitos de direito, o legislador vê-se, então, obrigado a enfrentar e solucionar o que a ciência não consegue resolver (RADBRUCH, 1934, p. 106).

Deste modo, pela impossibilidade de estabelecer o que seja justo, deve-se estabelecer o que deve ser jurídico. Assim, afirma Radbruch (1934, p. 106-107) (tradução nossa): "Em vez de um ato de verdade, que é impossível, é necessário um ato de autoridade. O relativismo desemboca no positivismo".

Finalmente, a partir das ideias sobre o dualismo e o relativismo expostas acima, pode-se afirmar que a concepção jusfilosófica de Radbruch deve ser entendida como uma consideração valorativa do direito, podendo ser chamada de teoria do direito justo.

\section{O conceito e ideia de direito em Gustav Radbruch}

Radbruch, coerente com o seu pensamento, atribui à sua teoria jusfilosófica grande importância aos valores e à dualidade; considera o direito uma obra humana, uma realidade cultural, sendo possível entendê-lo somente a partir da ideia do direito. Sobre o seu conceito de direito assevera Radbruch (2004, p. 47):

O conceito de direito é um conceito cultural, quer dizer, um conceito de uma realidade referida a valores, uma realidade cujo sentido é o de estar a serviço de valores. O direito é a realidade que tem o sentido de servir ao valor jurídico, à ideia do direito. $\mathrm{O}$ conceito de direito cumpre-se, portanto, na idéia do direito.

"O conceito do Direito é a ideia do Direito, o ser ao dever ser" (RADBRUCH, 1951, p. 46) (tradução nossa). O direito é um fato que pertence ao mundo do ser e não é possível derivar o conceito de direito indutivamente, empiricamente, dos fenômenos jurídicos; para isso seria necessário que os fenômenos jurídicos já fossem conhecidos como fenômenos do direito, "[...] portanto, o conceito de Direito é um conceito a priori, que somente pode ser obtido pela via dedutiva" (RADBRUCH, 1951, p. 46) (tradução nossa).

O direito em Radbruch é um fenômeno cultural e, por consequente, o conceito de direito é cultural. Neste ponto, o autor adverte que os conceitos culturais não são conceitos axiológicos nem conceitos ontológicos, mas, conceitos que se referem a valores. Mais adiante, de modo detalhado, será visto que a ideia de direito é formada por ideias de valor.

Deste modo, para finalizar o conceito de direito, vale destacar que, além de o conceito de direito orientarvol.11, no. 02, Rio de Janeiro, 2018. pp. 1015 - 1036 
se pela ideia do Direito, deve ser positivo, normativo, de caráter social e geral, e assim o define: "[...] o 'Direito' pode, pois, definir-se como o conjunto de normas gerais e positivas que regulam a vida social" (RADBRUCH, 1951, p. 47) (tradução nossa).

O mais relevante este ensaio, sobre o conceito de direito de Radbruch, é a sua derivação da ideia de Direito; neste aspecto, este autor afirma:

Neste mesmo sentido podemos dizer, finalmente, que o Direito é a soma ou o conjunto dos fatos críticos cujo sentido se reduz em realizar a justiça, se realiza ou não; é Direito aquilo que tem como sentido pôr em prática a ideia do Direito. O conceito de Direito orienta-se pela ideia do Direito, o que significa que a segunda precede logicamente o primeiro. (RADBRUCH, 1951, p. 47.) (Tradução nossa).

A ideia de direito é composta por três valores: justiça, adequação ao fim e segurança jurídica. Radbruch (1951, p. 31), seguindo sua proposta axiológica, pontifica que o Direito deve pautar-se na justiça e esta deve ser meta do legislador. Porque "[...] a justiça é um valor absoluto, como a verdade, o bem ou a beleza; um valor que descansa, portanto, em si mesmo, e não deriva de outro superior" (tradução nossa).

A justiça, como um dos elementos da ideia de direito, tem como fundamento central a igualdade. A igualdade é tratada em duas dimensões: igualdade absoluta entre bens, denominada de justiça igualitária ou niveladora; e a igualdade relativa ou proporcional na forma de tratar diferentes pessoas, que é chamada de justiça distributiva (RADBRUCH, 2004, p. 49).

A justiça igualitária é a justiça que se encontra nas relações de coordenação e se associa ao direito privado; de outra forma, a justiça distributiva está presente nas relações de subordinação e supraordenação e ligase ao direito público (RADBRUCH, 2004, p. 50).

A justiça igualitária é a justiça entre as pessoas com igualdade de direitos, o que pressupõe um ato da justiça distributiva, que outorga a todos os participantes a mesma equiparação, a mesma capacidade de relação e o mesmo status. Assim, para Radbruch a justiça distributiva é a forma originária da justiça, na qual se encontra a ideia de justiça pela qual o conceito de direito deve orientar-se (RADBRUCH, 2004, p. 50).

Contudo, pondera que, apesar de orientar-se pela justiça, não é possível alcançar a "[ ... ] ideia diretriz exaustiva para a derivação do conteúdo do direito" (RADBRUCH, 2004, p. 107). Isso, porque a justiça instrui a tratar os iguais como iguais e os desiguais como desiguais, contudo não diz como qualificar os iguais e outros como desiguais, determinando tão somente uma relação, mas, não, o modo de tratamento (RADBRUCH, 2004, p. 107-108). Portanto, a concepção de justiça de Radbruch é formal:

A ideia de justiça é uma ideia formal. Não dá respostas a duas perguntas, senão pressupõe mais para não contestar. Supõe trato igual para os iguais e trato desigual para os desiguais, de acordo com a mesma pauta, mas, sem poder dizer-nos: 1) a quem deve considera-se igual e a quem desigual; nem 2) com hão de ser tratados os iguais e os desiguais. (RADBRUCH, 1951, p. 33-34.) (Tradução nossa.).

Em virtude de a justiça ter apenas o caráter formal, e por não transmitir à maioria das normas um 
conteúdo, torna-se necessária a introdução de um segundo elemento na ideia de direito: a adequação ao fim, também chamando em outras passagens de finalidade, utilidade ou bem comum.

Mas a grande maioria das normas jurídicas somente recebe da ideia de justiça sua forma, a igualdade de tratamento para todos e a generalidade da regulamentação legal. Seu conteúdo deve determinar-se, em compensação, por outro princípio que, por isso mesmo forma parte também da ideia do Direito: o princípio da adequação ao fim. (RADBRUCH, 1951, p. 35.) (Tradução nossa.).

Entende Radbruch (1951, p. 35) a adequação ao fim com aquilo que o direito deve ser: "Por 'fim no Direito' não deve entender-se, no entanto, para estes efeitos, um fim empiricamente perseguido, a ideia de fim, do que deve ser" (tradução nossa.). Este segundo elemento refere-se aos propósitos substantivos que o direito deve realizar e que, uma vez determinados, permitirá dotar de conteúdo a forma da justiça.

Radbruch (1951, p. 35-36) extrai este segundo elemento da ética, como afirma: "Enquanto que o conceito da justiça é incumbência da filosofia do direito, a ideia de fim tem que retirar da ética" (tradução nossa). A ética para o referido autor divide-se em duas partes: a teoria dos deveres e a teoria dos bens, sendo que esta última é responsável pela formação do conteúdo imposto pela moral. O fim do direito pode fazer referência tanto aos bens como aos deveres morais.

A teoria dos bens morais, por sua vez, divide-se em três grupos de valores: o individualista, que compreende os valores da personalidade individual; o superindividual, que reconhece os valores das personalidades coletivas; e os transpersonalistas, que proclama como supremos bens e os valores da cultura (RADBRUCH, 1951, p.36).

As formas de convivência desses valores correspondem: à sociedade individualista, à coletividade supraindividualista e à comunidade transpersonal. Estas formas sociais assumem ideais políticos, respectivamente: a liberdade, considerada por partidos liberais, democráticos e socialistas - o poder ou nação, que é a base dos partidos autoritários ou conservadores; a cultura, que num primeiro momento se ligou ao catolicismo político, mas não chegou a ter relevância em nenhum partido político (VIGO, 2008, p. 30).

Não é possível estabelecer racionalmente entre essas três classes uma hierarquia de valores de modo inequívoco, não é possível sobrepor uma classe de valores sobre a outra sem sacrificar uma das classes.

Os propósitos e valores supremos do Direito só variam de acordo com os estados sociais dos diferentes tempos e diferentes povos, mas que são processados, ademais, subjetivamente, de diferente modo segundo as pessoas, de acordo com seu senso de Direito, a sua maneira de conceber o Estado, a sua posição partidária, seu credo religioso ou a sua convicção de mundo. A decisão tem que ser tomada pelo indivíduo, descendo até as entranhas de sua própria personalidade, como um assunto privativo de sua consciência. (RADBRUCH, 1951, p. 37-38.) (Tradução nossa).

O problema da finalidade ou da adequação do direito recai no relativismo axiológico; ante a impossibilidade de definir o direito, surge, então, a necessidade de estabelecer o jurídico e aspirar a garantir o prescrito. 
Se a adequação ao fim, figura na ideia do direito como complemento necessário de uma justiça definida em termos formais, resulta que o relativismo impede determinar seu conteúdo, vale dizer, impede determinar a justiça substantiva, porque é impossível determinar entre as classes de valores qual seja superior ou preferível objetivamente à outra. Essa impossibilidade de determinar o conteúdo do princípio da adequação exige a introdução de um terceiro elemento na ideia de direito: segurança jurídica.

A inclusão da segurança jurídica na ideia de direito significa a necessidade de um direito positivo, ante a impossibilidade de determinar objetivamente os propósitos do direito, de precisar o justo num sentido estrito. Neste sentido, afirma Radbruch (1951, p. 39):

O problema do fim do Direito, formulado em relação aos bens éticos, tinha que desembocar necessariamente no relativismo. E na impossibilidade de definir o Direito justo, por essa razão, tem que se conforma, pelo menos, com estatuí-lo, por meio de um poder que tenha, ademais, a força necessária para impor o estatuído. Não é outra a justificação do Direito Positivo, pois a exigência da segurança jurídica somente pode ser cumprida mediante a positividade do Direito. (Tradução nossa).

Para Radbruch (1951, p. 40) a segurança jurídica é: “[...] a segurança do Direito, mesmo” que não deve confundir-se com a "[... ] segurança por meio do Direito, a segurança que o Direito nos confere ao garantir nossa vida ou nossos bens contra o assassinato, o roubo etc. -, pois esta já está implícita no conceito de adequação ao fim" (tradução nossa).

A segurança jurídica definida por Radbruch como um terceiro elemento da ideia de direito parece tratarse de um tipo especial de segurança, relativa ao próprio direito, e independente de seu conteúdo concreto, o que seria diferente da segurança que o direito impõe, por sua vez, ao garantir às pessoas certo estado de coisas.

A segurança jurídica implica em quatro exigências para conformar-se à ideia de direito: o direito deve ser positivo, o que equivale para Radbruch (1951, p. 40) que ele seja estatuído em leis. O direito deve ser preciso, tem que ser "[...] baseado em fatos e que não se remeta aos juízos de valor do juiz em torno do caso concreto, mediante critérios gerais como o da 'boa-fé' ou dos 'bons costumes"” (tradução nossa). Os fatos nos quais o direito se baseia devem ser praticáveis e, por fim, o direito deve ser estável, o direito não deve ser mudado com frequência, e também não deve existir legislação incidental que facilite a produção de leis para situações singulares (RADBRUCH, 1951, p. 40).

Com a inserção do terceiro elemento, segurança jurídica, à ideia de direito, a positividade torna-se "[ ... ] o próprio pressuposto de sua justiça: tanto o ser positivo é parte do conceito de direito justo quanto o ser justo em seus conteúdos é tarefa do direito positivo" (RADBRUCH, 2004, p. 108).

De acordo com Radbruch (1951, p. 43), essas três ideias de valor que compõem a ideia de direito completam-se entre si, mas, ao mesmo tempo, contradizem-se em si. A contradição entre esses elementos ocorre da seguinte maneira: se se sustenta que o importante é o fim, a adequação do direito, esta afirmação é contestada, argumentando que a justiça é a base e fundamento de todo direito. Por outro lado, se se defende a segurança 
jurídica, a ponto de asseverar que o direito positivo tem que reger e aplicar-se, ainda que sacrificando outros valores jurídicos, esta asseveração pode ser contestada pela afirmação de que o direito positivo ao impor-se de modo incondicional seria fonte de injustiça. "Existem, portanto, no seio da ideia de direito, antagonismos latentes que reclamam uma solução" (RADBRUCH. 1951, p. 43) (tradução nossa).

Neste sentido afirma Radbruch sobre a contradição entre os valores da ideia de Direito:

Salus populi suprema lex esto, diz-se, de uma parte, o que equivale sustentar que somente importa o final; iustitia fundamentum regnorum, contesta-se isso: a justiça é a base e fundamento de todo Direito. De um lado se diz: fiat iustitia, pereat mundus, ou seja: o Direito positivo tem que reger e aplicar-se, ainda que às custas de sacrificar todos os demais valores jurídicos; de outro lado se afirma que o Direito positivo, ao impor-se de um modo incondicional, poderia degenerar por si mesmo na injustiça: summum ius, summa iniuria. (RADBRUCH, 1951, p. 13.) (Tradução nossa).

Com o objetivo de solucionar esses antagonismos, Radbruch (2004, p. 109) estabelece uma hierarquia dos valores que compõem a ideia de direito, na qual se encontra no topo a justiça, haja vista que para este autor os valores da ideia de direito se subordinam à exigência da justiça.

Nesta hierarquia a justiça e segurança jurídica estão e devem estar acima da adequação ao fim. Para Radbruch (1951, p. 43-44) não é possível atribuir à adequação ao fim uma validade universal, haja vista o relativismo axiológico e, ainda, pelo fato de que uma adequação ao fim pode ser utilizada de modo indevido por meio de uma suposição ou como um pretexto, o que pode gerar arbitrariedades.

No mesmo sentido, na obra Filosofia do direito, Radbruch afirma sobreposição da segurança e da justiça em relação à adequação ao fim;

Dos três elementos da ideia do Direito somente para o segundo [adequação ao fim] vale a utilidade, a autolimitação relativista. Os outros dois, a justiça e a segurança jurídica, situam-se acima das antinomias das concepções do direito e do Estado, acima da luta dos partidos políticos. (RADBRUCH, 2004, p. 108-109.)

É justamente nesse ponto em que se encontra a razão de ser da segurança jurídica, qual seja, estatuir um direito claro e inequívoco em face das diferentes exigências que a adequação ao fim reivindica (RADBRUCH, 1951, p. 44).

Contudo, o conflito mais importante estabelece-se entre a segurança jurídica e a justiça. Antes de entrar nesse tema, é preciso ressaltar que o pensamento radbruchiano aqui tratado é aquele apresentado após a Segunda Guerra Mundial. A segurança jurídica objetiva a aplicação do direito positivo, ainda que injusto. Esta uniformidade da aplicação do direito positivo injusto, ou seja, uma aplicação igual, hoje e amanhã, sem distinções, corresponde à igualdade que essencialmente forma a justiça, contudo, neste caso, é o injusto que é repartido justamente entre todos, portanto requer um restabelecimento da justiça, por meio de um tratamento desigual.

Para Radbruch (1951, p. 43-44), a segurança jurídica é uma forma de justiça, de modo que se verifica um conflito da justiça consigo mesma. Assim, afirma: "Sendo, portanto, a segurança jurídica uma forma da justiça, temos que a luta da justiça com a segurança jurídica representa um conflito da justiça com ela mesma" (tradução 
nossa).

Pelo fato de a segurança jurídica ser uma faceta da justiça, este conflito não pode ser decidido de maneira unívoca, mas trata-se de uma questão de grau. Assim, após a Segunda Guerra Mundial, para Radbruch, quando a injustiça do direito positivo alcança proporções em que a segurança jurídica garantida pelo direito positivo já não representa nada em comparação com o grau de injustiça, assim o direito positivo injusto deve ceder lugar à justiça:

Por isso este conflito não pode ser decidido de uma maneira unívoca. Trata-se de uma questão de grau: ali em que a injustiça do direito positivo alcança tais proporções, que a segurança jurídica garantida pelo direito positivo já não representa nada em comparação com aquele grau de injustiça, não cabe dúvida de que o direito positivo injusto deverá ceder lugar à justiça. (RADBRUCH, 1951, p. 44.) (Tradução nossa).

Esta é a ideia de direito que o conceito de direito de Radbruch persegue. Esta ideia de direito revela a preocupação em positivar o direito e de obedecer-lhe, como forma de torná-lo mais seguro, contudo é possível notar o abrandamento do legalismo do cumprimento a qualquer custo do direito positivo em casos extremos.

\section{O EQUILÍBRIO ENTRE A POSITIVIDADE E A JUSTIÇA}

A possível conversão de Radbruch nos anos em que ocorreu o nazismo e após a Segunda Guerra Mundial teria influenciado sobremaneira a sua concepção sobre o positivismo e, claro, a sua compreensão sobre a segurança jurídica.

Alguns autores sustentam que, após a Segunda Guerra Mundial, Radbruch teria mudado o seu pensamento; um desses autores é Hart, que afirma:

[Ele,] Radbruch, compartilhou a doutrina "positivista" até a tirania nazista, mas foi convertido por esta experiência, por isso o seu apelo a outros homens para discordar da doutrina da separação do direito e da moral tem especial pungência de uma retratação. (HART apudPAULSON, 2006, p. 18.) (Tradução nossa).

Por outro lado, autores, como E. Wolf, defendem que Radbruch não teria modificado sua opinião a respeito da forma de resolver os conflitos entre a justiça e a segurança jurídica, mas sempre teve a opinião de que não existe um critério unívoco para a solução desse conflito.

Talvez tenha ocorrido com a teoria de Radbruch fato semelhante que, segundo Alexy teria ocorrido com a fórmula da injustiça extrema, apenas um ajuste. Para Robert Alexy (2008c, p. 382) a fórmula da injustiça extrema não era nova, mas, sim, o resultado de um pequeno ajuste no sistema jurídico de Radbruch, que disse: "[...] para chegar à sua famosa fórmula depois de 1945, Radbruch teve que dar um ajuste no sistema” (tradução nossa). Esse sistema a que Alexy se refere trata-se da ideia de direito e a presença dos três valores, o ajuste seria a hierarquia desses valores, mais precisamente quando Radbruch destaca que existe um conflito entre justiça e segurança jurídica, e que a preferência pela segurança jurídica não pode nunca chegar a ponto de permitir uma injustiça extrema. 
Todavia, este trabalho não se aterá às polêmicas se houve ou não uma conversão de Radbruch, entretanto, não resta dúvida entre os autores de que Radbruch nos seus últimos escritos trouxe novidades para o seu pensamento. Pode-se destacar que modificou o alcance do jusnaturalismo, anunciado com mais precisão, demonstrando o seu conteúdo, os direitos humanos e o efeito da sua ausência no direito positivo; como consequência dessa mudança tem-se a regra para dirimir os conflitos entre justiça e segurança jurídica; no caso do direito positivo, violar gravemente os direitos humanos, devendo a justiça prevalecer sobre a segurança jurídica, a fim de evitar a extrema injustiça; nos demais casos, deve prevalecer a segurança jurídica, portanto apresenta um critério mais preciso para resolver este conflito do que antes; e ainda, deixa mais claro que a segurança jurídica se trata de uma forma da justiça.

O que se revela de mais importante é que houve no trabalho Radbruch uma mudança na relação entre direito positivo (segurança jurídica) e a justiça. No quinto minuto do texto Cinco minutos de filosofia, publicado pela primeira vez como circular dirigida aos estudantes da Universidade de Heidelberg, em 1945, afirma:

Há também princípios fundamentais de direito que são mais fortes do que todo e qualquer preceito jurídico positivo, de tal modo, que toda a lei que os contrarie não poderá deixar de ser privada de validade. Há quem thes chame de direito natural e quem lhes chame direito racional. (RADBRUCH, 1979, p. 417).

Radbruch (2009, p. 12), no texto A renovação do direito, de 1946, deixa clara a necessidade da mitigação do direito positivo por meio do direito natural. Nesse texto, reflete sobre a necessidade de reconstruir o direito após o período nazista na Alemanha, afirma que “[...] os juristas estão confrontados com a difícil missão de limpar os escombros nos lugares destruídos e levantar a nova construção do direito" (tradução nossa). Primeiramente deve-se restabelecer o respeito à lei, erigindo a segurança jurídica, renovando o Estado, reconstruindo o Estado de Direito. Com essa primeira tarefa, impõe-se uma segunda, que parece opor-se à primeira. É o retorno da ciência do direito à milenar sabedoria, comum à Antiguidade, à Idade Média cristã e ao Iluminismo, de considerar a existência de um direito mais alto que a lei, um direito natural, um direito divino, um direito racional, nas palavras de Radbruch (2009, p. 12-13), um direito supralegal.

Essa mitigação do positivismo em Radbruch (2009, p. 12-13) deve-se ao conceito de direito estabelecido entre os juristas alemães por décadas, como um direito positivo dominante, inquestionável, com a sua doutrina de que lei é lei, que foi responsável, na visão de Radbruch, por inúmeras injustiças na forma da lei.

No artigo Injustiça legal e direito supralegal, publicado em 1946, com o título original Gesetzliches Unrecht und übergesetzliches Recht, Radbruch reflete sobre os problemas da legalidade e justiça que surgiram em alguns processos judiciais que se ocuparam de fatos ocorridos durante o totalitarismo nacional-socialista alemão, e assim retoma o conflito entre segurança e justiça, iniciado na obra Introdução à filosofia do direito, como na obra Filosofia do direito, demonstrando, nitidamente, o abrandamento do positivismo, por meio da fórmula da injustiça extrema: 
O conflito entre a justiça e a segurança jurídica deve resolver-se com a primazia do direito sancionado pelo poder, ainda que seu conteúdo seja injusto e inconveniente, a não ser que a contradição da lei positiva com a justiça alcance uma medida tão insuportável, que deva considerar-se "como falso direito" e ceder à justiça. É impossível traçar uma linha mais nítida entre os casos de arbitrariedade legal e das leis válidas apesar de seu conteúdo incorreto; mas outro limite poderá distinguir-se com toda claridade: quando nunca se procurou a justiça, onde a igualdade, que integra o núcleo do direito, ali a lei não é somente "direito incorreto", mas também carece por completo da natureza do direito, pois não se pode definir o direito, inclusive o direito positivo, de outra maneira que como uma ordem e estatuto, que de acordo com seu sentido estão determinados a servir a justiça. (RADBRUCH, 2009, p. 34 35.) (Tradução nossa)

Segundo Alexy (2008c, p. 357), a Fórmula de Radbruch, acima descrita, consta de duas partes, denominadas de fórmula da intolerância e fórmula da negação. Na fórmula da intolerância as leis positivas perdem a sua validade jurídica se sua contradição com a injustiça alcançar uma medida insuportável. $\mathrm{Na}$ fórmula da negação as leis positivas perdem a natureza jurídica quando não atribuem a estas leis, de modo consciente, a igualdade, que para Radbruch é o núcleo da justiça, ou seja, é quando as leis são propositivamente formuladas de forma injusta. A fórmula da intolerância tem um caráter objetivo, aplica-se na medida da injustiça, enquanto que a fórmula da negação tem caráter subjetivo voltado para as intenções do legislador.

A divisão da fórmula da injustiça extrema, nas fórmulas da intolerância e negação, permite verificar duas situações muito importantes na aplicação da fórmula da injustiça extrema. Segundo José Antonio Seoane Rodríguez (2002, p. 786), as normas insuportavelmente injustas, a fórmula da intolerância, na qual a lei positiva, como direito injusto ou incorreto, cede à justiça, para Radbruch segue sendo Direito, ainda que injusto. Na negação consciente da justiça a que se refere a segunda parte da fórmula, a lei não é somente direito injusto, mas também carece de natureza jurídica.

A relevância desta divisão está no fato de ficar claro que na fórmula da negação é negada a condição jurídica à lei extremamente injusta, enquanto que na fórmula da intolerância a lei extremamente injusta, apesar da sua condição, ainda tem o status de direito.

Ainda no que se refere à Fórmula de Radbruch, apesar de não explicitar no trecho anteriormente referido, que é comumente citado para demonstrar a fórmula da injustiça extrema, é válido destacar o limite da injustiça posto por Radbruch (2009, p. 36), que é a violação dos direitos humanos; assim afirma: "O caráter de Direito está ausente ademais em todas as leis que tratavam os seres humanos como bestas e os negavam os direitos humanos" (tradução nossa).

O direito natural em Radbruch tem o seu conteúdo concreto, é constituído pelos direitos humanos, e servem de um critério material de validade, que funciona ao menos negativamente, se o direito positivo é injusto a ponto de ferir os direitos humanos, então deixa de ser direito, ou seja, num conflito entre a segurança jurídica e justiça, se os direitos humanos são afetados, deve prevalecer a justiça (MANRIQUE, 2005, p. 281).

Ao contrário do que se possa pensar, de uma leitura primeira e superficial da obra de Radbruch, que, em 
decorrência dos problemas como o nazismo, iria negar em absoluto o positivismo e as leis positivas, se manifesta que, após doze anos do regime nacional-socialista, no qual para ele houve a negação da segurança jurídica, é necessário esgrimir considerações jurídico-formais, buscando a justiça e, ao mesmo tempo, respeitar a segurança jurídica, que é uma parte da justiça, e construir um Estado de Direito que realize concomitantemente a segurança jurídica e a justiça.

Somos da opinião de que, ao longo de doze anos de negação da segurança jurídica, é mais necessário do que nunca esgrimir considerações "jurídico-formais" contra as tentações que, como se compreende, podem facilmente dar-se em todo aquele que haja presenciado os doze anos de perigo e opressão. Nós temos que buscar a justiça, ao mesmo tempo respeitar a segurança jurídica, pois ela mesma é uma parte da justiça e constituir de novo um Estado de direito, que realize esses dois pensamentos no possível até a saciedade. (RADBRUCH, 2009, p. 41.) (Tradução nossa).

O que Radbruch (2009, p. 37) pretendia era uma saída para casos como o do nazismo, superando um positivismo legalista. Radbruch depositou toda a capacidade defensiva diante do abuso da legislação nacionalsocialista, a fim de evitar o regresso de um Estado de ilegalidade semelhante, sobre o que afirma: "Isto vale para o futuro. Diante da arbitrariedade legal dos doze anos passados, devemos buscar a realização das exigências da justiça com o mínimo possível de sacrifício da segurança jurídica" (tradução nossa).

Enfim, para além da discussão se Radbruch se converteu ou não após a Segunda Guerra Mundial, o que se conclui na teoria deste jusfilófoso é uma mitigação de um positivismo legalista, típico da Escola da Exegese, pela via da busca da justiça, sem se esquecer da segurança jurídica. O modo como a Fórmula de Radbruch coloca a justiça e a segurança jurídica nos pratos da balança faz com que grande parte dos positivistas como dos nãopositivistas concorde que o direito consiste em algo mais que a pura regulação de condutas, ordens e o exercício da coação, e que o Direito também formula uma pretensão de justiça.

\section{CONCLUSÃO}

A eterna busca da certeza pelo ser humano reflete nas relações sociais, principalmente, no direito. A busca pela segurança, no direito, liga-se ao pensamento positivista, recebendo a denominação de segurança jurídica. Sem dúvida alguma, instituto necessário ao direito, a fim de evitar arbitrariedade. Todavia, o positivismo legalista também é fonte de arbitrariedades, como teria ocorrido, para alguns juristas, no nazismo. Um positivismo estrito, é sim, fonte de injustiça, tem-se como exemplo o caso da Lei da Anistia e do habeas corpus do ex-deputado Rubens Paiva.

Apesar disso, são institutos necessários e importantes ao direito, em outras palavras, essenciais ao direito. Por isso que, do mesmo modo que se objetiva a segurança do direito, busca-se também atender à justiça, assim torna-se importante o equilíbrio entre a positividade do direito e a justiça, pois nem tudo que está posto é justo.

Gustav Radbruch foi um dos pensadores do direito que se ateve a necessidade de equilibrar estes 
elementos no direito, para isso formula uma ideia de direito, da qual deriva o conceito de direito de Radbruch, composta de três valores: justiça, adequação ao fim e segurança jurídica. Sendo que cada um desses valores se completam, mas ao mesmo tempo, contradizem-se em si. Para solucionar esta contradição entre os valores da ideia de direito estabeleceu uma hierarquia entre os valores, esta hierarquia passou, então, a compor a ideia de direito.

A partir desse escalonamento, os valores da justiça e segurança jurídica estão acima da adequação ao fim. Em relação à hierarquia entre a justiça e a segurança jurídica é que se estabelece o conflito mais importante, ponto central desse ensaio, amago do equilíbrio entre o direito posto e a justiça estrita.

Para Radbruch a segurança jurídica é uma forma de justiça. Dessa maneira, a solução do conflito é uma questão de grau, devendo a segurança jurídica ceder lugar à justiça quando o direito positivo for extremamente injusto.

A fórmula da injustiça extrema dá o equilíbrio entre os elementos da ideia de direito de Radbruch, levando em consideração a necessidade do direito positivo, mas com vistas a alcançar a justiça. O equilíbrio entre a positividade e a justiça é imperativo para o pleno exercício de um direito justo, minimizado possíveis arbitrariedades. Gustav Radbruch, por meio de sua teoria do direito contribui para harmonizar o direito posto e a justiça.

\title{
THE SEARCH FOR A BALANCE BETWEEN THE POSITIVITY OF LAW AND THE REALIZATION OF JUSTICE: A RADBRUCH VISION
}

\begin{abstract}
In times of little belief in the positive law due to judicial decisions that, sometimes, the contrary, important is shed light on an old but still relevant discussion, which is the harmony between legal security and justice. In this perspective, the objective of this article is to outline ways to balance the elements of the balance between legal certainty and justice. As a theoretical framework of the research was used the thinking of the philosopher Gustav Radbruch. The methodology used was the legal-comprehensive and exploratory, having as research source books, specific articles and jurisprudence. All this has allowed us to achieve the result that the need to harmonize legal certainty and justice is indispensable. And it was concluded that in radbruchian thinking the extreme injustice formula gives the necessary balance between the elements, legal security and justice, of Radbruch's idea of law, considering the need for positive law, but with a view to achieving justice.
\end{abstract}

Keywords: Legal Positivism; Justice; Legal certainty; Balance; Extreme injustice; Right. 


\section{REFERENCIAS}

AFONSO, Elza Maria Miranda. O direito e os valores: reflexões inspiradas em Franz Brentano, Max Scheler e Hans Kelsen. Revista CAAP, Belo Horizonte, n. 8, p. 15-62, 1999.

ALEXY, Robert. Una defensa de la Fórmula de Radbruch. In: VIGO, Rodolfo (Org.). La injusticia extrema no es derecho: de Radbruch a Alexy. México: Fontamara, 2008c. p. 355-391.

BOBBIO, Noberto. O positivismo jurídico: lições de filosofia do direito. São Paulo: Ícone, 2006.

FASSÒ, Guido. Jusnaturalismo. In: BOBBIO, Noberto (Org.). Dicionário de política. 11. ed. Brasília: Editora UnB, 1998.

FERRAZ JÚNIOR, Tércio Sampaio. A ciência do direito. 2. ed. São Paulo: Atlas, 1980.

Introdução ao estudo do direito: técnica, decisão, dominação. 2. ed. São Paulo: Atlas, 1994.

GLISSEN, John. Introdução histórica ao direito. 2. ed. Lisboa: Fundação Calouste Gulbenkian. 1995.

LATORRE, Angel. Introdução ao direito. Coimbra: Almedina, 2002.

MACHADO, Roberto Denis. O positivismo jurídico. In: TRIVISONNO, Alexandre Gomes Travessoni. Dicionário de teoria e filosofia do direito. São Paulo: LTr, 2011.

MANRIQUE, Ricardo García. Radbruch y el valor de la seguridad jurídica. Anuario de Filosofía del Derecho, Madrid, n. 21, p. 261-286.

MONTESQUIEU, Charles de Secondat. Del'esprit des lois. Paris: Garnier Frères, [19--].

RADBRUCH, Gustav. Cinco minutos de filosofia do direito. In: RADBRUCH, Gustav. Filosofia do direito. Coimbra: Arménio Amado - Editor, 1979. Apêndice II. p. 415-418.

Filosofia do direito. São Paulo: Martins Fontes, 2004.

Introducción a la filosofía del derecho. México: Fundo de Cultura Económica, 1951.

Relativismo y derecho. 2. ed. Bogotá: Editorial Themis S.A., 2009.

Le relativisme dans la philosophie de droit. Archives de Philosophie du Droit et de Sociologie Juridique, Paris, n. 12, p. 105-110, 1934.

SEONE RODRÍGUEZ, Jose Antonio. La doctrina clásica de la lex iniusta y la fórmula de Radbruch: un ensayo de comparación. Anuario da Facultade de Dereito da Univerdidade da Coruña, Coruña, n. 6, p. 761-790, 2002.

SICHES, Luis Recaséns. Experiencia jurídica, naturaleza de la cosa y lógica razonable. México: Fundo de Cultura Económica, 1971.

PAULSON, Stanley. On the background and significance of Gustav Radbruch's post-war papers. Oxford Journal of Legal Studies, Oxford, v. 26, n. 1, p. 17-40, 2006.

VIGO, Rodolfo. La axiología jurídica de Gustav Radbruch. In: VIGO, Rodolfo (Org.). La injusticia extrema no es derecho: de Radbruch a Alexy. México: Fontamara, 2008. p. 21-56. 
Quaestio Iuris

Trabalho enviado em 18 de janeiro de 2018. Aceito em 04 de março de 2018. vol. 11, n. 02, Rio de Janeiro, 2018. pp. 1015-1036 DOI: $10.12957 /$ rqi.2018.32136 